\title{
PRECARIOUS COEXISTENCE
}

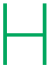

istory will probably remember 2020 as a turning

point. Globally, the Covid-19 pandemic slowed

down the relentless advance of the Anthropocene

and cast doubt on the capitalist development

model. Meanwhile, at the local scale, the principles

that governed us in the last four decades were also questioned, to the point that we now have the chance to define a new beginning. After the landslide victory of the 'apruebo' option in the plebiscite of October 25, Chile is moving towards a constitutional process that will allow us to define the rules of our coexistence as a country - a new constitution - in a democratic and just manner.

Thus, this year we have faced a paradox: as guinea pigs of unprecedented confinement strategies on a global scale, our survival depended on the suspension of some of the most basic forms of coexistence. However, precisely because of this, we realized that we cannot exist without others. And even the very definition of 'others' has already fallen short. We no longer speak only of the inclusion of minorities and the marginalized, but also of other species: plants, trees, animals, or even a virus. We have coexisted with them all this year.

This issue of ARQ is a space to make these various forms of coexistence visible. The photographic report portrays the walls within the city as the medium where the yearnings for dignity exist side-by-side after the 2019 uprising. In the interview with the acclaimed philosopher Emanuele Coccia, we are able to grasp some of his ideas on the cohabitation with non-human species, such as plants or animals. Along these lines, the Animalesque Group shows us how architecture can learn from the way in which animal construct spaces. Tironi and Hermansen present us with an experiment in human-animal coexistence where failure was the key to understanding these more-than-human beings. Office for Political Innovation, for its part, invites us to participate in a project where the cosmopolitical approach - in which all species and things have the same rights - is used to awaken children's curiosity. Soyka, Liu, and Ebersol analyze interspecies coexistence as one of Gandhi's contemporary heritage in India. Sebastián Irarrázaval proposes a citadel to protect vulnerable children where they can develop the ability to fend for themselves. Valiente, Valiente, Sánchez, and Rodríguez-Casellas narrate the casual connection between two cities located on different sides of the Pacific. Greene, de Abrantes, and Trimano analyze the problematic relationship between metropolitan and rural culture. Azócar and Catrón show us how a simple element in the public space can trigger new forms of interaction. Elke Schlack argues that what regulations 

the forms of cohabitation in Santiago as an alternative to solve the housing deficit. Pérez, Quintanilla, and their team present a project that ensures the conjunction of different architectures. Pedro Livni manages different programs in the center of a Montevideo block. And finally, in the debate, two positions are confronted on a crucial issue regarding the constitutional process: the possible coexistence of the Mapuche Nation within the State of Chile. This number, however, leaves open a fundamental question: how to understand this year?

A possible answer is given by Anna L. Tsing when she affirms that "progress stopped making sense" (2015:25). Lacking an idea of a better future, what characterizes our time is precariousness, that "state of acknowledgment of our vulnerability to others," where we realize that "to survive, we need help, and help is always the service from another, with or without intent"(Tsing, 2015:29). Both the pandemic and the social unrest in Chile are demonstrations of the fragile condition of our existence. The mere fact that the most precarious jobs have become 'essential' proves Tsing right. We learned, by force, that hiding precariousness only leads to anguish and that, instead, its socialization opened the door to political changes - unthinkable just a couple of years ago. When precariousness is the norm, there is no possibility of existence without a pact of coexistence.

The point is not that coexistence is precarious because it is at risk of not materializing, but that the very precariousness in which we all live makes coexistence necessary. If our planet can collapse from a virus or from global warming, then all of our lives are precarious. No one is safe.

Not even ARQ. In its forty years, our magazine has become a space where different ways of understanding architecture have interacted. Perhaps it is that flexibility that allows us to continue looking to the future and not to the past. Bad or bad, we are the same age as the current political constitution of Chile. But, unlike the Magna Carta, our precariousness has forced us to adapt to the times. Hopefully, it is that precariousness - opposite to the rigidity of the 1980 constitution - that allows us to continue to exist for many more years. At least, we already managed to survive this strange 2020. ARQ

\section{Bibliografía / Bibliography}

TSING, Anna Lowenhaupt. The mushroom at the end of the world: on the possibility of life in capitalist ruins. Princeton: Princeton University 